\title{
Rain Rate and Rain Attenuation Prediction for Satellite Communication in Ku Band Beacon over TURKSAT Golbasi
}

\author{
Yasin Burak Kaya ${ }^{1}$, ID Umit Cezmi Yilmaz ${ }^{2}$ \\ ${ }^{1}$ Corresponding Author; Türksat Satellite Communication and Cable TV Operation AS. Satellite Control Center, \\ 06839, Golbasi, Ankara, Turkey; ybkaya@ turksat.com.tr \\ 2Türksat Satellite Communication and Cable TV Operation AS. Satellite Control Center; \\ cyilmaz@turksat.com.tr
}

Received 4 August 2021; Revised 04 December 2021; Accepted 13 December 2021; Published online 31 December 2021

\begin{abstract}
The most effective technique used to measure rain attenuation is experimentally monitoring the received signal strength of satellite beacon. A satellite beacon is a signal which does not modulated and sends to the ground in constant frequency with a specifically designed power. Beacon signals are used by ground station antenna users to track the satellite easily. The satellite operators generally choose beacon signal at the $\mathrm{Ku}$ Band frequency band since this band is more resistant to rain attenuation. Ku band satellite system performance describe by the contribute of rainfall rate and rain attenuation. This paper includes the comparison of rain attenuation in Ku band beacon and takes as a reference ITU - 838 model caused by rain fall rate in TURKSAT premises. It is compared by calculating that how signals affected from rain between 2012 and 2019 observations for a TURKSAT satellite and in this measurement, both theoretical formula and data are used.
\end{abstract}

Keywords: TURKSAT, rain attenuation, ku band beacon signal, ITU-838

\section{Introduction}

The most dominant sources of attenuation in satellite communication systems come from atmospheric losses. These losses arise from rain, snow and dense clouds individually or as a combined effect. Rain attenuation becomes more dominant loss for carrier frequencies above $10 \mathrm{GHz}$. Precipitation rates (determining the amount of rain) and cumulative precipitations show differences from region to region on earth. Calculating and predicting path losses are therefore not accurate without comprehensive meteorological information obtained locally. In ITU-R proposal [1], earth is divided into regions according to precipitation rates. However, precipitation rates vary because of geographical locations of countries and climate conditions [2]. There might be some discrepancies on precipitations between ITU$\mathrm{R}$ proposals and real case, considering that the ITU-R should have been used more conservative approach. That's why, the operators are motivated to revisit the rain attenuation models on their region. Rain precipitation model of ITU-R designated Turkey region ' $\mathrm{K}$ '. The main motivation for this work is to analyze whether there is differences between region $\mathrm{K}$ values versus long term rain statics maintained under all local weather conditions. The data used in this study belongs to the Golbasi /Ankara /Turkey for the dates starting from June 2012 up to September 2019 at yearly basis. Ku band beacon signals coming from an operational TURKSAT GEO satellite are used. They are examined according to weather conditions, space propagation (or path) losses, cable losses and atmospheric losses. This paper is organized as follows. In section 2, link budget of path losses of the TURKSAT Ku band beacon signal is provided. Section 3 presents rain losses comparing ITU-R-838 and TURKSAT data. In section 4, results are summarized, and a solution method is proposed to compensate for the differential errors that might endanger the reliability and even the continuity of communication. 
Kaya et al.

\section{Link Budget of TURKSAT Satellite Ku Band Beacon}

Satellite operators broadcast at high frequencies such as $\mathrm{C}, \mathrm{Ku}$ or $\mathrm{Ka}$ band. $\mathrm{Ku}$ band used most commonly to minimize such attenuations. Frequency of the C-band is small compared to the $\mathrm{Ku}$ and $\mathrm{Ka}$ bands, and the antenna diameter is quite large compared to the other frequencies used. In C-band, more power is required to transmit the signal to the satellite. This is not a preferred frequency. As the frequency increases, the antenna diameters will decrease proportionally. For satellite operations, larger antennas with tracking capabilities are used in $\mathrm{Ku}$ and $\mathrm{Ka}$ band and this kind of antennas cost more comparing the others [3], [4], [5], [6]. One of the biggest motivation for calculating satellite losses due rain as accurate as possible is financial gain especially on the uplink side. For this study, two different antennas were selected and their parameters are given in Table 1.

Table 1 Türksat Satellite Beacon link budget information for Two Antennas [6]

\begin{tabular}{|c|c|c|c|}
\hline Parameter & Symbol & Antenna-A & Antenna-B \\
\hline Frequency: & $\mathrm{f}$ & $11.120 \mathrm{GHz}$ & $11.120 \mathrm{GHz}$ \\
\hline Diameter: & $\mathrm{d}$ & $7.2 \mathrm{~m}$ & $13.2 \mathrm{~m}$ \\
\hline Efficiency & $\eta$ & 0.6 & 0.6 \\
\hline Satellite EIRP & EIRP & $15 \mathrm{dBW}$ & $15 \mathrm{dBW}$ \\
\hline Free Space Loss Downlink & LS & $204.88 \mathrm{~dB}$ & $204.88 \mathrm{~dB}$ \\
\hline Receiver Gain & Gr & $56.26 \mathrm{dBW}$ & $61.53 \mathrm{dBW}$ \\
\hline Receiver System Temp & Ts & $127 \mathrm{~K}$ & $125.8 \mathrm{~K}$ \\
\hline Receiver G/T & G/T & $35.26(\mathrm{~dB} / \mathrm{K})$ & $40.30(\mathrm{~dB} / \mathrm{K})$ \\
\hline Received power & Pr & $-103.62 \mathrm{dBm}$ & $-98.152 \mathrm{dBm}$ \\
\hline Received Power LNA & Pr (LNA) & $-43.62 \mathrm{dBm}$ & $-68.152 \mathrm{dBm}$ \\
\hline Gain of LNA & GLNA & $60 \mathrm{dBm}$ & $30 \mathrm{dBm}$ \\
\hline Bandwidth & BW & $2 \mathrm{kHz}$ & $2 \mathrm{kHz}$ \\
\hline Gas Absorption Losses & Lg & $1 \mathrm{~dB}$ & $1 \mathrm{~dB}$ \\
\hline Pol. and Misalign losses & Lp & $1 \mathrm{~dB}$ & $1 \mathrm{~dB}$ \\
\hline Rain Rate & R0.01 & $16.35 \mathrm{~mm} / \mathrm{h}$ & $15.36 \mathrm{~mm} / \mathrm{h}$ \\
\hline Carrier to Noise Ratio & C/N0 & $70.28(\mathrm{~dB} / \mathrm{Hz})$ & $75.70(\mathrm{~dB} / \mathrm{Hz})$ \\
\hline
\end{tabular}

\section{Rain Fade Calculations}

\subsection{Based on ITU-R}

Rain fade which is the main source of error in path loss calculations, changes with frequency, location, polarization and rainfall rate. The amount of loss due to rain can be calculated using

$$
\mathrm{L}_{\mathrm{RAIN}}=\gamma_{\mathrm{R}} \mathrm{D}_{\mathrm{S}}
$$

Where $L_{\text {RAIN }}$ is the rain loss (or attenuation) in $\mathrm{dB}, \gamma_{\mathrm{R}}$ is the specific attenuation in $\mathrm{dB} / \mathrm{km}$, and $\mathrm{D}_{\mathrm{S}}$ is the path length through the troposphere in $\mathrm{km}$ which is measured from the freezing point (zero-degree isotherm, the level at which it is assumed that all rain originates) in the atmosphere to the receiving antenna. To calculated the rain loss, latitude $(\varphi)$ and longitude of the earth station should be known. Inaddition the antenna altitude of the station; hs km, the frequency of operation, and the polarization of the signal should also be known. Schematic presentation of an Earth-space path is shown in Fig.1 


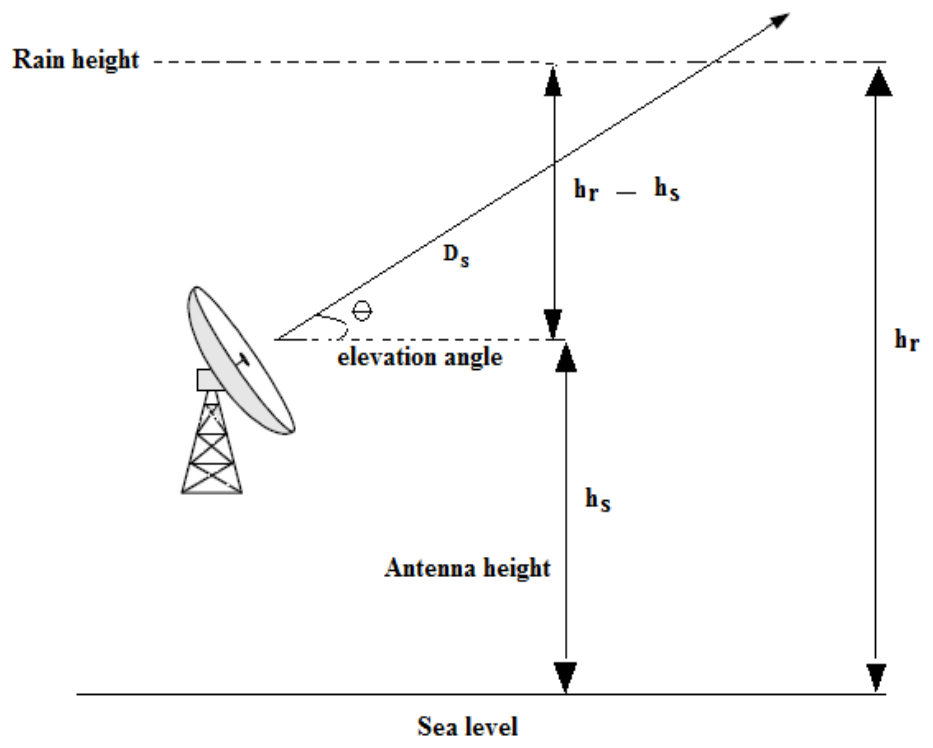

Figure 1. Schematic representation of an Earth-space path [7], [8], [9], [10]

$$
D_{s}=\frac{(\mathbf{h r}-\mathbf{h s})}{\sin \theta}
$$

Where $h_{r}$ is the rain height from the sea level, $h_{S}$ is the distance of the satellite receiving antenna to the sea level, and $\Theta$ is the elevation angle. ITU-R Recommendation P.839 relates rain height to location which is reproduced in Table 2.

Table 2 Rain height, $\mathrm{h}_{\mathrm{r}}$ for different regions of the Earth [11]

\begin{tabular}{|c|c|c|}
\hline Latitude $\varphi$ & $\mathbf{h}_{\mathbf{r}}(\mathbf{k m})$ & Region \\
\hline $\begin{array}{c}\varphi>23 \text { North } \\
0<\varphi<23 \\
\text { North }\end{array}$ & $5-0.075(\varphi-23)$ & $\begin{array}{c}\text { Northern hemisphere } \\
\text { (except North America \& }\end{array}$ \\
\hline & $5.2-0.075(\varphi-35)$ & $\begin{array}{c}\text { Northern hemisphere } \\
\text { (except North America \& }\end{array}$ \\
\hline $\begin{array}{c}\text { Northern hemisphere North } \\
\text { America \& Europe west of }\end{array}$ \\
\hline $0 \geq \varphi \geq 21$ South & 5 & Southern hemisphere \\
\hline $21 \mathrm{~S} \geq \varphi \geq 71$ & $5+0.1(\varphi+21)$ & Southern hemisphere \\
\hline 71 South $>\varphi$ & & Southern hemisphere \\
\hline
\end{tabular}

The elevation angle $\Theta$ and the rain path $\mathrm{D}_{\mathrm{s}}$ can be calculated as $43.145^{\circ}$ and $3.8976 \mathrm{~km}$ respectively. Besides, Antenna-A was used between 2012-2015 whose $\mathrm{h}_{\mathrm{s}}$ is 1086 meters, Antenna-B was used between 2016-2019 whose $\mathrm{h}_{\mathrm{S}}$ is 1095 meters from the sea level. The elevation angle $\Theta$ and the rain path $D_{\mathrm{s}}$ can be calculated as of $43.145^{\circ}$ and $3.885 \mathrm{~km}$ respectively. Using equation the specific attenuation, $\gamma_{R}$ can be found from for each year [6].

$$
\gamma_{\mathrm{R}}=\mathrm{kR}^{\alpha}
$$

where $\mathrm{k}$ (either $\mathrm{k}_{\mathrm{H}}$ or $\mathrm{k}_{\mathrm{V}}$ ), and $\alpha$ (either $\alpha_{\mathrm{H}}$ or $\alpha_{\mathrm{V}}$ ) are frequency-dependent parameters given in ITU-R Recommendation P-838 [8] as shown in the first three rows of Table 3. If the beacon signal is horizontally polarized then $\mathrm{k}_{\mathrm{H}}$, and $\alpha_{\mathrm{H}}$ are used in equation (3).

Table 3 Frequency-dependent coefficients for estimating specific rain attenuation [7]

\begin{tabular}{|c|c|c|c|c|}
\hline $\begin{array}{c}\text { Frequency } \\
(\mathbf{G H z})\end{array}$ & $\mathbf{k H}_{\mathbf{H}}$ & $\boldsymbol{\alpha}_{\mathbf{H}}$ & $\mathbf{k v}$ & $\boldsymbol{\alpha}_{\mathbf{v}}$ \\
\hline 11.000 & 0.01772 & 1.2140 & 0.01731 & 1.1617 \\
\hline 11.120 & 0.01840 & 1.2097 & 0.01790 & 1.1563 \\
\hline
\end{tabular}


Kaya et al.

TURKSAT carrier frequency is $11.120 \mathrm{GHz}[6]$ and corresponding; $\mathrm{k}$ and $\alpha$ factors that are calculated using the ITU recommendation $\mathrm{P} 838$ [7]. The rainfall rate $\mathrm{R}$ is another parameter necessary to calculate the attenuation coefficient, $\gamma_{R}$ Table 4 links the rainfall rates to the percentage of the time it is exceeded in any year by rainfall regions of the world [5] as per ITU recommendation. It indicated before [5], Turkey falls in region $\mathrm{K}$. For $\gamma_{\mathrm{R}}$ calculations, it is assumed that the rainfall rate that will only be exceeded $0.01 \%$ of the time for a satellite terminal in Turkey, Golbası (i.e. the rainfall rate that will give 99.99\% availability). From that, the rain rate to be used as per ITU recommendation becomes $42 \mathrm{~mm} / \mathrm{h}$. TURKSAT is located in the central Anatolian region of Turkey, in the Gölbaş1 of Ankara. It has $39^{\circ} 46$ 'N and 32 $49^{\prime}$ E values as coordinates. Since the meteorology station in the center of Gölbaş1 is $20 \mathrm{~km}$ between TURKSAT premises, measurements is taken with the meteorology equipment (Davis Vantage Pro2) in the center of the ground station. Since meteorology equipment and antennas are in the same place, it enabled us to get more accurate results. Annual rain rate and rain attenuation are calculated according to the data obtained from the measuring device located at the ground station [6].

Table 4 Rainfall rate $\mathrm{R}$ to the percentage of the time it is exceeded in any year by region [11]

\begin{tabular}{|c|c|c|c|c|c|c|c|c|c|c|c|c|c|c|c|}
\hline $\begin{array}{c}\text { \%R } \\
\text { time } \\
\text { exceeded }\end{array}$ & $\mathbf{A}$ & $\mathbf{B}$ & $\mathbf{C}$ & $\mathbf{D}$ & $\mathbf{E}$ & $\mathbf{F}$ & $\mathbf{G}$ & $\mathbf{H}$ & $\mathbf{J}$ & $\mathbf{K}$ & $\mathbf{L}$ & $\mathbf{M}$ & $\mathbf{N}$ & $\mathbf{P}$ & $\mathbf{Q}$ \\
\hline 1.0 & $<0.1$ & 0.5 & 0.7 & 2.1 & 0.6 & 1.7 & 3 & 2 & 8 & 1.5 & 2 & 4 & 5 & 12 & 24 \\
\hline 0.3 & 0.8 & 2 & 2.8 & 4.5 & 2.4 & 4.5 & 7 & 4 & 13 & 4.2 & 7 & 11 & 15 & 34 & 49 \\
\hline 0.1 & 2 & 3 & 5 & 8 & 6 & 8 & 12 & 10 & 20 & 12 & 15 & 22 & 35 & 65 & 72 \\
\hline 0.03 & 5 & 6 & 9 & 13 & 12 & 15 & 20 & 18 & 28 & 23 & 33 & 40 & 65 & 105 & 96 \\
\hline 0.01 & 8 & 12 & 15 & 19 & 22 & 28 & 30 & 32 & 35 & 42 & 60 & 63 & 95 & 145 & 115 \\
\hline 0.003 & 14 & 21 & 26 & 29 & 41 & 54 & 45 & 55 & 45 & 70 & 105 & 95 & 140 & 200 & 142 \\
\hline 0.001 & 22 & 32 & 42 & 42 & 70 & 78 & 65 & 83 & 55 & 100 & 150 & 120 & 180 & 250 & 170 \\
\hline
\end{tabular}

\subsection{Rain Fade Based on Long Term Meteorological Data at Golbasi/Ankara}

ITU-R P.618-12 recommends to use $42 \mathrm{~mm} / \mathrm{h}$ rain rate for rainfall attenuation for region ' $\mathrm{K}$ '. Whereas, as can be seen from Table 5 and Table 6 , smaller the rain rates are calculated by ITU-R838 Model by using the measured values. The related tables show also the calculated values and actual values derived from antenna system. There are minor differences between the calculated and measured $\mathrm{L}_{\mathrm{RAIN}}$ due to the differences in antenna system (i.e, diameter, rain sensor and rain blower).

Table 5 Rain rates for years Turksat Golbasi region [6], [12], [13]

\begin{tabular}{|c|c|c|c|c|c|c|}
\hline Year & $\begin{array}{c}\text { Rain Rate at } \\
0.01 \%(\mathrm{~mm} / \mathrm{hr})\end{array}$ & $\begin{array}{c}\mathbf{E}^{\circ} \\
\text { Antenna-A }\end{array}$ & $\mathbf{D}_{\mathrm{s}}(\mathbf{k m})$ & $\begin{array}{l}\text { Calculated } \\
\mathbf{L}_{\text {RAIN }}(d B)\end{array}$ & $\begin{array}{l}\text { Measured } \\
\mathbf{L}_{\text {RAIN }}(d B)\end{array}$ & $\begin{array}{l}\text { Difference } \\
\text { (dB) }\end{array}$ \\
\hline 2012 & $9.54 \mathrm{~mm} / \mathrm{h}$ & 43.146 & 3.897 & 1.099 & 0.529 & 0.570 \\
\hline 2013 & $10.21 \mathrm{~mm} / \mathrm{h}$ & 43.146 & 3.897 & 1.193 & 0.533 & 0.660 \\
\hline 2014 & $16.35 \mathrm{~mm} / \mathrm{h}$ & 43.146 & 3.897 & 2.110 & 0.912 & 1.198 \\
\hline 2015 & $14.78 \mathrm{~mm} / \mathrm{h}$ & 43.146 & 3.897 & 1.867 & 0.757 & 1.110 \\
\hline
\end{tabular}

Table 6 Rain rates for years Turksat Golbasi region [6], [12], [13]

\begin{tabular}{|c|c|c|c|c|c|c|}
\hline Year & $\begin{array}{c}\text { Rain Rate at } \\
\mathbf{0 . 0 1 \%} \\
(\mathbf{m m} / \mathbf{h r})\end{array}$ & $\begin{array}{c}\mathbf{E}^{\circ} \text { Antenna- } \\
\mathbf{B}\end{array}$ & $\mathbf{D}_{\mathbf{s}}(\mathbf{k m})$ & $\begin{array}{c}\text { Calculated } \\
\mathbf{L}_{\text {RAIN }}(\mathbf{d B})\end{array}$ & $\begin{array}{c}\text { Measured } \\
\mathbf{L}_{\text {RAIN }}(\mathbf{d B})\end{array}$ & $\begin{array}{c}\text { Difference } \\
(\mathbf{d B})\end{array}$ \\
\hline 2016 & 13.54 & 43.145 & 3.885 & 1.674 & 0.630 & 1.374 \\
\hline 2017 & 12.06 & 43.145 & 3.885 & 1.455 & 0.589 & 0.866 \\
\hline 2018 & 15.36 & 43.145 & 3.885 & 1.950 & 0.715 & 1.235 \\
\hline 2019 & 14.23 & 43.145 & 3.885 & 1.778 & 0.678 & 1.100 \\
\hline
\end{tabular}


Kaya et al.

\section{Conclusion}

While examining the losses in satellite communication link budgets, calculation of margins become very significant. Climatic conditions and rain precipitation value of Golbasi region are different from the region ' $\mathrm{K}$ ', determined by ITU-R. Considering this region, same climatic area as South Asia and North Iraq does not always give a correct result [5]. Rain precipitation rate in tropical areas is different from continental climate. It has precipitation rate between $10-25 \mathrm{~mm} / \mathrm{h}$ in accordance with data taken from meteorology and it is rarely above $25 \mathrm{~mm} / \mathrm{h}$. When precipitation rate gets higher, loss rate also gets higher according to ITU-R 838 model. According to this study, the value of $42 \mathrm{~mm} / \mathrm{h}$ seem to be very conservative value comparing the long term meteorological rain data for Turkey [13], [14], [15]. Considering the region ' $\mathrm{K}$ ' rain rate is $42 \mathrm{~mm} / \mathrm{h}$, this corresponds to about $6.6 \mathrm{~dB}$ rain attenuation for TURKSAT location. On the other hand, for Antenna-A case, the maximum observed value at 2014 was $16.35 \mathrm{~mm} / \mathrm{h}$ which corresponds to $2.11 \mathrm{~dB}$ rain attenuation. In this case, the diameter of Antenna-A can be reduced from 7.2 meters to 4.5 meters as per calculations result. For Antenna-B, the maximum observed rain rate was $15.36 \mathrm{~mm} / \mathrm{h}$ at 2018 which corresponds to $1.95 \mathrm{~dB}$ of rain loss. In that case, the diameter of Antenna-B can be reduced from 13.2 meters to 7.7 meters as per calculations. It is shown with this research that ITU-R-612 has conservative values comparing the actual results. The major gain from the study is to have opportunity of reduction of antenna diameter as well as minor profits due to the other units of the antenna systems (i.e HPA, LNA).

\section{Acknowledgments}

We would like to thank Turksat AS for its' invaluable support.

\section{References}

[1] Dr. Y. L. Hui, W. K. Sain, Y. L. Sin et al., " Overcoming Rain Fade Obstacle-Understanding Singapore's," Rain Dynamics and Feasible Countermeasures Against Rain Fading-DSTA Horizons., pp. 6-15.

[2] S. J. Mandeep and E. J. Allnut, "Rain attenation Predictions at Ku-Band in South East Asia Countries, " Progress in Electromagnetics Research, PIER 76., pp. 65-74, 2007.

[3] C. J. Kikkert and B. Bowthorpe, "A Satellite Beacon Receiver using Digital Signal Processing Techniques, ” Progress in Electronic Research, PIER 76., pp. 65-74,2007.

[4] C .J. Kikkert, B. Bowthorpe, G. H. Allen, "Satellite Beacon Receiver Improvement using Digital Signal Processing," ISSPA '96., pp. 517-520, Gold Coast, Australia, August 1996.

[5] H. J. J. Ameen.," Rain effect on Ku Band satellite system," Electrical and Electronics Engineering: An International Journal (ELELIJ)., vol. 4, no. 2, May 2015.

[6] Türksat Satellite Communication and Cable TV Operation A.Ş / Ground Stations /Document., “ $11.120 \mathrm{GHz} \mathrm{Ku}$ band Beacon Telemetry Information, ”, 2012-2019.

[7] Specific attenuation model for rain for use in prediction methods (2005, September, 29), E27367 (03-05): RECOMMENDATION ITU-R P.838-3

[8] O. Olabisi and E. A. Oladeji., " Effects of Rain on Vertical and Horizontal Polarized Ku Band Radio Propagation in Tropical Region," (IJCST)., vol. 6, no. 1, January-February 2018.

[9] Propagation data and prediction methods required for the design of Earth-space telecommunication systems (2015, August, 11), E70000, (206/3): RECOMMENDATION ITU-R P.618-12

[10] A.Samed, D. F. Diba, and D.Y. Choi., " A Survey of Rain Fade Models for Earth-Space Telecommunication Links-Taxonomy,Methods and Comparative Study," Remote Sens,2021,13,1965. https://doi.org/10.3390/rs13101965., 2021.

[11] P. Charlesworth., "Notes on a Technıque to estimate Rain Margins/ University of Wales,", 20102015.

[12] B. I. Asianuba, and U. Agomuo., "Effect of Rain on Satellite Television Transmission," (EJET)., vol. 4, no. 4, 2019. 


\section{Kaya et al.}

[13] Turkish State Meteorological Service Department of Golbasi: Station no: 17134., "Amount of rain year, day and hours,", 2012-2014.

[14] Y. A. Abdulrahman, A. T. Rahman, and A. K. S. Rahim., “ A new Rain Attenuation Conversion Technique for Tropical Regions," Progress in Electromagnetics Research B., no. 26, pp. 53-67, 2010.

[15] C. M. Kestwal, S. Joshi, and S. L. Garia., "Prediction of Rain Attenuation and Impact of Rain in Wave Propagation at Microwave Frequency for Tropical Region (Uttarakhand, India)," International Journal of Microwave Science and Technology., vol. 2014, ID 958498, pp. 6, 11 June-2014. 